\title{
Daniel Etcheverry Burgueño: Montevideo, 20/01/1961 - Porto Alegre, 17/07/2020
}

\section{Pilar Uriarte Bálsamo}

\section{(2) OpenEdition}

1 Journals

Edición electrónica

URL: http://journals.openedition.org/aa/6731

DOI: 10.4000/aa.6731

ISSN: 2357-738X

Editor

Programa de Pós-Graduação em Antropologia Social (UnB)

Edición impresa

Paginación: 354-358

ISSN: 0102-4302

Referencia electrónica

Pilar Uriarte Bálsamo, «Daniel Etcheverry Burgueño: Montevideo, 20/01/1961 - Porto Alegre, 17/07/2020», Anuário Antropológico [En línea], v.45 n.3 | 2020, Publicado el 16 septiembre 2020, consultado el 28 abril 2021. URL: http://journals.openedition.org/aa/6731 ; DOI: https://doi.org/ 10.4000/aa. 6731

\section{(c) $)(1)(9$}

Anuário Antropológico is licensed under a Creative Commons Atribuição-Uso Não-Comercial-Proibição de realização de Obras Derivadas 4.0 International. 


\title{
Daniel Etcheverry Burgueño Montevideo, 20/01/1961 - Porto Alegre, 17/07/2020
}

\author{
Pilar Uriarte Bálsamo • Universidad de la República - Uruguay \\ Doctora en Antropología Social (PPGAS-UFRGS). Profesora Adjunta del Dpto. de Antropología Social y Coor- \\ dinadora Académica del Centro de Estudios Interdisciplinarios Migratorios en Facultad de Humanidades y \\ Ciencias de la Educación de la Universidad de la República, Montevideo, Uruguay. Investigadora Nivel I del \\ Sistema Nacional de Investigadores, Agencia Nacional de Investigación e Innovación.
}


El 17 de julio, después de pelear contra el cáncer por casi un año y de haberle ganado una vez hace años, nos dejó Daniel; el antropólogo, el profesor, el amigo. Para mí, además de un colega era una especie de hermano mayor y por eso es un honor escribir estas líneas.

Al comenzar me pregunto en qué idioma hacerlo. Así como en muchas otras cosas, conversar con Daniel significaba transgredir lenguas y traspasar territorios y no creo que haya uno u otro código que lo represente más o mejor. Finalmente, me decido por el español, porque es el idioma en que siempre acabábamos conversando o discutiendo las cosas importantes. En esas reflexiones, peleas y divagues fue que nos reinventamos uruguayos y brasileros y nos hicimos habitantes de muchos mundos, antropólogos e investigadores de la movilidad humana.

Daniel vivió muchas vidas, por algunas solo pasó y en otras se detuvo. Migrante y estudioso de las migraciones llegó a la antropología y a la movilidad humana después de mucho andar. Un andar irreverente y rebelde, que empezó por renegar del corsé que el Uruguay de la dictadura militar intentaba ponerle, pero que estuvo siempre orientado por una apuesta a vivir, conocer y comprender. Cada partida implicaba para él una apertura, un nuevo mundo para habitar, otra vida a ser vivida. De esa experiencia, alimentada por una permanente curiosidad y el compulsivo rechazo a cualquier convención social surge el antropólogo que muchos de nosotros conocimos, una persona única y especial.

Por los años 2000 comenzó sus estudios de grado en Ciencias Sociales en la Universidade Federal de Rio Grande do Sul, con orientación de Ari Pedro Ouro. Fue una apuesta por conquistar los estudios universitarios y conquistar Brasil también, al investigar sobre religiosidad afro. Pertenecer, poder pensar y decir sobre un mundo del que se es parte de hecho, pero no necesariamente de derecho es siempre una cuestión para las personas que migran; y ese desafío lo tomó de lleno.

Una vez culminada esa etapa, comenzó un nuevo desafío, que implicaba volver sobre el Uruguay y la emigración, reelaborar su experiencia e incorporarla a su ser investigador. Significó integrar experiencias personales y colectivas con preocupaciones teóricas y preguntas analíticas. En el marco del Núcleo de Antropologia e Cidadania del Programa de Pós-Graduação em Antropologia Social de la UFRGS, y con orientación de Denise Jardim, el foco de investigación se volcó hacia las migraciones y las formas en que los documentos y otros dispositivos de control estatal y social configuran las trayectorias e identidades de quienes atraviesan fronteras. El título de su disertación de maestría: "Identidade não é documento: narrativas de ruptura e continuidade nas migrações contemporâneas", defendida en 2007, es una muestra de cómo la experiencia personal, atravesada por una dosis justa de reflexividad puede transformarse en la clave de una etnografía sólida, o de otro modo; como toda etnografía es siempre y de forma radical un diálogo intersubjetivo entre el investigador y sus interlocutores. A partir de esta investigación publicó el capítulo "A documentação de estrangeiros no Brasil: seus caminhos e significados"(2007) del libro Cartografias da imigração: Interculturalidade e Politicas Públicas de la colección del Núcleo de Antropologia e Cidadania (PPGAS, UFRGS). En el libro Políticas da diversidade: (in)visibilidade, pluralidade e cidadania em 
uma perspectiva antropológica de esa misma colección, algunos años más tarde publicaría el capítulo "A atuação dos mediadores da promoção da cidadania e a problemática da visibilidade” (2013).

El foco en la documentación como dispositivos de control de la población y en las formas en que diferentes dispositivos de construcción del migrante como un actor construido social y políticamente cede lugar al interés por las formas de resistencia, organización y deconstrucción de los mecanismos de control de la movilidad y de las formas de participación de la población extranjera en la sociedad de acogida. En ese proceso y poniendo en diálogo las realidades latinoamericanas con la española (donde realizó una estancia doctoral) surge la tesis de doctorado "Vivo en un mundo y quiero otro": Um estudo etnográfico sobre os discursos migratórios e as modalidades de controle dos imigrantes em Buenos Aires, Madri e Porto Alegre, que defendió en 2011, en el PPGAS-UFRGS, también bajo la orientación de Denise Jardim. En el desarrollo de esta investigación aparece la preocupación por comprender las diferentes formas de mediación política y social en las que se construye, configura y moldea la posibilidad o imposibilidad de participación de las personas migrantes y los colectivos organizados.

De estas experiencias de investigación publicó una serie de artículos, como "La construcción social del inmigrante. Estudio antropológico comparativo de las migraciones en Buenos Aires y Porto Alegre" (2009); "La construcción y desconstrucción del miedo: experiencias de inmigrantes frente a la autoridad policial” (2010) o "Sobre Burocracias, Documentos e Sujeitos Imigrantes: Otimização e Flexibilidade na Vivência da Mobilidade" (2016). En estos artículos es posible visualizar el desarrollo de esa línea de interés y como preocupaciones sociales y preguntas analíticas. Los medios de comunicación y las formas de comunicar la experiencia migratoria comenzaron a incorporarse también al análisis, participando en publicaciones colectivas sobre la temática (2012).

Una de las características de su trabajo de investigación, es que no se interesaba únicamente por el producto obtenido, sino por el contexto social y humano en el que se insertaría la producción de conocimiento. Esto también estaba presente en su trabajo docente. En 2011 ingresó como profesor a la Universidad Federal do Pampa (UNIPAMPA), en Sao Borja. Allí trabajó apasionadamente, ilusionado con abrir caminos para que las ciencias sociales acompañaran a las nuevas generaciones a andar por sí mismas. Formó un taller etnográfico: Dilemas da vida na frontera, en la cual buscaba iniciar a los estudiantes de grado en los procesos de investigación; y realizó diversos proyectos de extensión, buscando ampliar los horizontes de las ciencias sociales al diálogo con la sociedad. En su interés por fortalecer el proceso de consolidación de una universidad joven, fuimos varios los y las antropólogas de Uruguay y Argentina invitadas a participar en jornadas académicas en Sao Borja. Siempre adelante con sus proyectos, fue muchas veces incomprendido por quienes lo rodeábamos. A pesar de nuestra incredulidad, en sus palabras nada era imposible.

En los últimos tiempos, a pesar de estar enfermo, continuaba proyectando y soñando, cosas que a cualquiera le parecerían imposibles, pero que sus amigos 
desconfiábamos de que en manos de Daniel eran posibles. A pesar de la fragilidad de su salud, nunca tiró la toalla y siguió apoyando y cuidando a quienes lo rodeaban, invirtiendo una vez más el orden de las cosas. Era una persona profundamente generosa y con el don de cuidar a todos. Por lo que representó como investigador, acercando personas, construyendo agendas de trabajo y reflexión, incentivando procesos de formación a todos los niveles, su ausencia representa una gran pérdida para la antropología regional.

Recebido: 27/07/2020

Aprovado: 03/08/2020 


\section{REFERÊNCIAS}

ETCHEVERRY, Daniel. A atuação dos mediadores da promoção da cidadania e a problemática da visibilidade. In: JARDIM, Denise; LÓPEZ, Laura (Org.). Políticas da diversidade: (in)visibilidade, pluralidade e cidadania em uma perspectiva antropológica. Porto Alegre: Editora da UFRGS, 2013. p. 59-72.

ETCHEVERRY, Daniel. A documentação de estrangeiros no Brasil: seus caminhos e significados. In: Denise Jardim (Org.). Cartografias da imigração: interculturalidade e políticas públicas. Porto Alegre: Editora da UFRGS, 2007. v. 1. p. 9-270.

ETCHEVERRY, Daniel. La construcción social del inmigrante. Estudio antropológico comparativo de las migraciones en Buenos Aires y Porto Alegre. Revista Iberoamérica Global, Universidad Hebraica de Jerusalén, 2008.

ETCHEVERRY, Daniel. La construcción social del inmigrante. Estudio antropológico comparativo de las migraciones en Buenos Aires y Porto Alegre. Iberoamérica Global - Revista Digital da Universidad Hebraica de Jerusalén, v. 2, p. 94-112, 2009.

ETCHEVERRY, Daniel. La construcción y desconstrucción del miedo: experiencias de inmigrantes frente a la autoridad policial. Ankulegi (Donostia), v. 14, p. 59-70, 2010.

ETCHEVERRY, Daniel. Sobre burocracias, documentos e sujeitos imigrantes: otimização e flexibilidade na vivência da mobilidade. REMHU (Brasília), v. 24, p. 115-129, 2016.

JARDIM, Denise; MAGALHAES, Nara; ETCHEVERRY, Daniel; URIARTE, Pilar. Tecnologias da comunicação e reconfiguração de identidades em processos migratórios entre África Ocidental, Europa e o Cone Sul. In: COGO, Denise; ELHAJJI, Mohamed; HUERTAS, Amparo (Orgs.). Diásporas, migrações, tecnologias da comunicação e identidades transnacionais. Barcelona: Instituto de la Comunicación (InCom-UAB), Universidad Autónoma de Barcelona, 2012. p. 67-84. 